CLINICAL STUDY

\title{
Post-operative hypothalamic lesions and obesity in childhood craniopharyngioma: results of the multinational prospective trial KRANIOPHARYNGEOM 2000 after 3-year follow-up
}

\author{
Hermann L Müller, Ursel Gebhardt, Carmen Teske ${ }^{1}$, Andreas Faldum ${ }^{2}$, Isabella Zwiener ${ }^{2}$, Monika Warmuth-Metz ${ }^{3}$, \\ Torsten Pietsch ${ }^{4}$, Fabian Pohl ${ }^{5}$, Niels Sörensen ${ }^{6}$, Gabriele Calaminus ${ }^{1}$ and on behalf of the study committee of \\ KRANIOPHARYNGEOM 2000 \\ Department of Pediatrics, Klinikum Oldenburg, Rahel-Straus-Strasse 10, 26133 Oldenburg, Germany, ${ }^{1}$ Department of Pediatric Oncology and \\ Hematology, University Hospital, 48149 Münster, Germany, ${ }^{2}$ Institute of Medical Biostatistics, Epidemiology and Informatics (IMBEI), University \\ Medical Center of the Johannes Gutenberg University Mainz, 55101 Mainz, Germany, ${ }^{3}$ Department of Neuroradiology, University Hospital, 97080 \\ Würzburg, Germany, ${ }^{4}$ Department of Neuropathology, University of Bonn, 35105 Bonn, Germany, ${ }^{5}$ Department of Radiooncology, University Hospital, \\ 93053 Regensburg, Germany and ${ }^{6}$ Department of Neurosurgery, Evangelisches Krankenhaus, 26121 Oldenburg, Germany \\ (Correspondence should be addressed to H L Müller; Email: mueller.hermann@klinikum-oldenburg.de)
}

\begin{abstract}
Background: Hypothalamic obesity has major impact on prognosis and quality of life (QoL) in childhood craniopharyngioma.

Patients and methods: For this study, 120 patients were prospectively recruited during 2001 and 2007 and evaluated after 3 years of follow-up (KRANIOPHARYNGEOM 2000). Body mass index (BMI) and QoL at diagnosis and 36 months after diagnosis were analysed based on the reference assessment of tumour localisation and post-surgical hypothalamic lesions. Treatment was analysed based on the neurosurgical strategy of 50 participating neurosurgical centres, the centre size based on the patient load.

Results: BMI SDS at diagnosis was similar in patients with or without hypothalamic involvement. Surgical lesions of anterior and posterior hypothalamic areas were associated with higher increase in BMI SDS during 36 months post-diagnosis compared with patients without or only anterior lesion $(+1.8$ BMISD, $P=0.033,+2.1$ BMISD; $P=0.011)$, negative impact on $Q 0 L$ in patients with posterior hypothalamic lesions. Surgical strategies varied among the 50 neurosurgical centres (three largesized, 24 middle-sized and 23 small-sized centres). Patients treated in small-sized centres presented with a higher rate of hypothalamic involvement compared with those treated in the middle- and largesized centres. Treatment in large-sized centres was less radical, and the rates of complete resection and hypothalamic surgical lesions were lower in large-sized centres than those of the middle- and smallsized centres. However, a multivariable analysis showed that pre-operative hypothalamic involvement was the only independent risk factor for severe obesity $(P=0.002)$.

Conclusions: Radical neurosurgical strategies leading to posterior hypothalamic lesions are not recommended due to the potential to exacerbate hypothalamic obesity and impaired QoL. Treatment should be confined to experienced multidisciplinary teams.
\end{abstract}

European Journal of Endocrinology 165 17-24

\section{Introduction}

Childhood craniopharyngioma tumours are rare embryogenic malformations of the sellar/parasellar area with low-grade histological malignancy, originating from ectoblastic remnants of Rathke's pouch $(1,2)$. Craniopharyngioma incidence is $0.5-2.0$ cases per million persons per year (3). Approximately, 30-50\% of all cases are diagnosed during childhood and adolescence. Craniopharyngioma represents $1.2-4 \%$ of all childhood intracranial tumours. In childhood and adolescence, its histological type is usually adamantinomatous, with cyst formation. Craniopharyngioma also occurs in adulthood, with peak incidence between the age 50 and 75 years, and in $14-50 \%$ of all cases with a papillary histological type as reported in hospital study (2). Despite high survival rates, the quality of life $(\mathrm{QoL})$ is frequently impaired due to adverse effects caused by the anatomical proximity of craniopharyngioma to the optic nerves, the optic chiasm, the pituitary gland and the hypothalamus. The most notable is severe hypothalamic obesity, which has a major negative impact on QoL in long-term survivors (4-8). An improvement of long-term prognosis requires 
the development of risk-adapted neurosurgical and radiooncological treatment strategies in a multidisciplinary approach.

The relationship between obesity and hypothalamic damage has been documented in animals $(1,2)$. Although there have been relatively few opportunities for systematic study of hypothalamic lesions in man $(9,10)$, there is controversy over whether and to what extent hypothalamic involvement is the apriori risk factor for adverse late effects (11), or whether obesity following surgery is more related to neurosurgical hypothalamic injury $(9,10,12-18)$.

This study presents the results of the first prospective multinational trial on childhood craniopharyngioma patients (KRANIOPHARYNGEOM 2000) (19), analysing the impact of tumour localisation, neurosurgical treatment strategies and extent of post-operative lesions on changes in QoL and body mass index (BMI) as a measure of obesity. A novel grading system for hypothalamic involvement/lesions was established and used to identify patients at risk for severe hypothalamic obesity and long-term impairment of QoL.

\section{Subjects and methods}

\section{Patients}

Between 2001 and 2007, 120 German, Austrian and Swiss patients $(58 \mathrm{f} / 62 \mathrm{~m})$ with an original diagnosis of craniopharyngioma were recruited from 76 centres at a median age of 10.0 years (range: $1.2-18.0$ years) (19). With a high degree of completeness $(>90 \%)$, data on neurosurgery and imaging were collected. Informed consent was obtained from patients and/or parents. The study was approved by the local standing committee on ethical practice (ClinicalTrials.gov NCT00258453).

\section{Neurosurgical management}

Based on the protocol of the prospective surveillance trial KRANIOPHARYNGEOM 2000 (19), there was no stratified or randomised question in terms of neurosurgical strategies. A surgical strategy preserving the integrity of optic and hypothalamic structures was recommended. The chosen intention to treat (radical versus incomplete resection) was stated by the treating neurosurgeon in advance of surgery. The actual degree of resection was evaluated based on the reference assessed post-operative imaging. Neurosurgical interventions were performed in 50 centres. Based on the patient load during the 6-year recruitment period, participating centres were categorised as small sized (one patient/6 years), middle sized (two to five patients $/ 6$ years) or large sized (more than five patients/ 6 years).

\section{Endocrine function}

Patients with craniopharyngioma required and received post-operative endocrine replacement for hypothyroidism $(87 \%)$, hypocortisolism $(78 \%)$, diabetes insipidus $(81 \%)$, hypogonadism $(46 \%)$ and GH deficiency $(81 \%)$.

\section{Evaluation of obesity}

Anthropometric data were prospectively obtained before and at 3-month intervals after diagnosis. BMI $\left(\mathrm{w} / \mathrm{h}^{2}\right.$; $\mathrm{w}=$ weight/kilogram, $\mathrm{h}=$ height/meter) was calculated for each subject at diagnosis and at 36 months after diagnosis and expressed as SDS according to RollandCachera et al. (20).

\section{Quality of life}

The Pediatric QoL Questionnaire (PEDQOL) defining health-related QoL within seven domains (21) was used to evaluate the patients' self-assessed QoL at 36 months after diagnosis. A baseline assessment of QoL at the time of diagnosis was not a mandatory part of the study protocol KRANIOPHARYNGEOM 2000. As QoL at diagnosis is frequently affected by clinical manifestations due to increased intracranial pressure, baseline self-assessment of QoL by PEDQOL will rather reflect these manifestations and cannot provide reliable data on QoL before diagnosis/surgery.

\section{Neuropathology}

In 109 of 120 patients, the histological diagnosis of craniopharyngioma (100 adamantinomatous type, two papillary type and seven unclassified) was confirmed by reference assessment. In the remaining 11 cases, histological diagnoses and classifications were assessed by local pathologists.

\section{Neuroimaging}

Cranial magnetic resonance imaging (MRI) was prospectively performed according to the recommendations as part of the trial protocol KRANIOPHARYNGEOM $2000(19,22)$ at diagnosis and at 3-month intervals during follow-up. The assessment of progression or recurrence was based on MRI and prospectively confirmed by reference panel in all cases. Tumour volume was estimated based on the maximal tumour diameters in three dimensions on MRI (volume $=\mathrm{a} \times$ $\mathrm{b} \times \mathrm{c} / 2$ ). Tumour progression was defined as $>25 \%$ increase in tumour volume.

Pre- and post-operative sagittal, coronar and axial MRI images were blind evaluated by a neuroradiologist, who classified the tumour according to the degree of hypothalamic involvement/surgical lesions: grade $0\left(0^{\circ}\right)$, no hypothalamic involvement/lesion (Fig. 1a and b); 

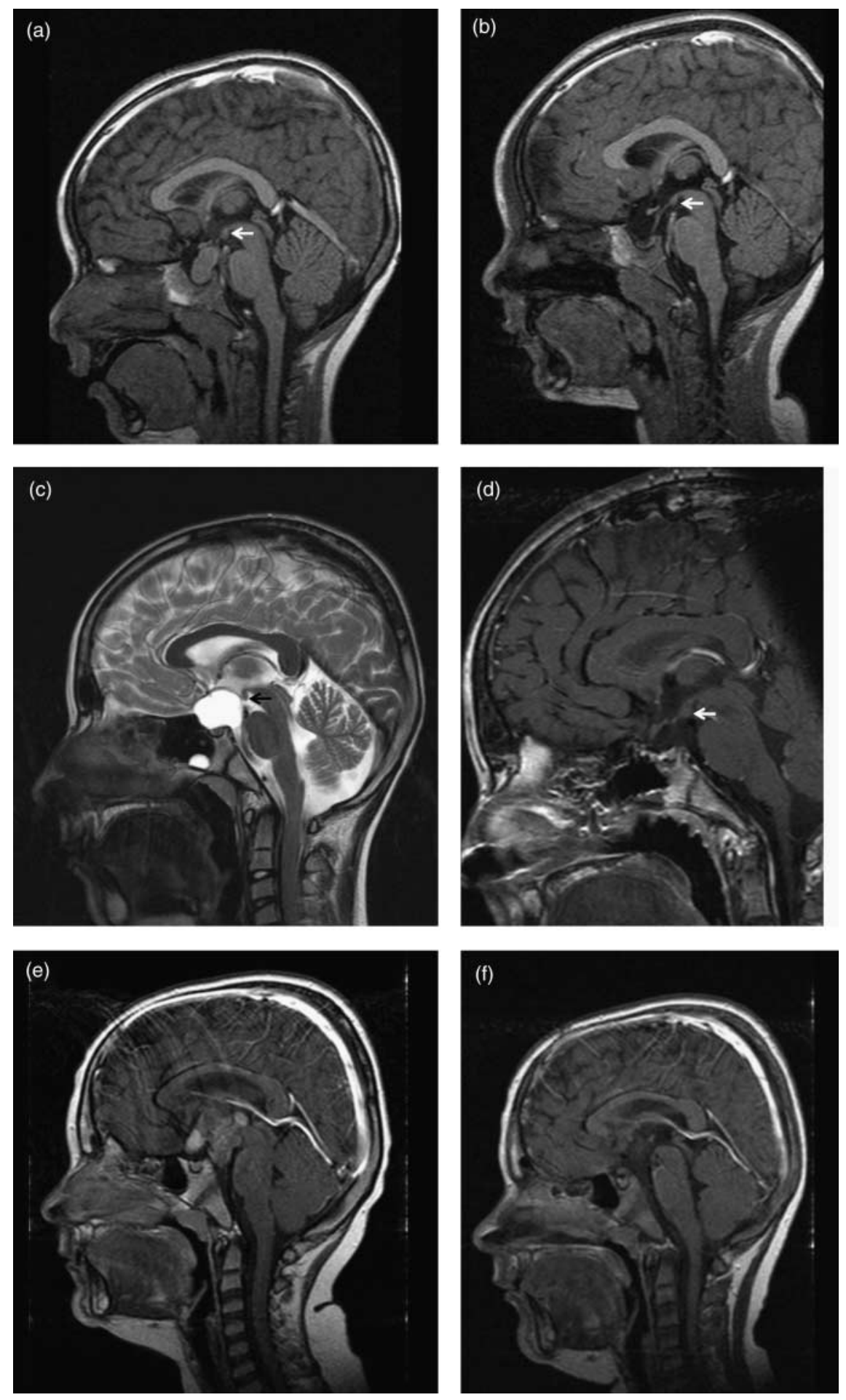

Figure $1 \mathrm{BMI}$ and MRI imaging at diagnosis and 36 months after surgery in three cases of childhood craniopharyngioma with different grade of hypothalamic involvement/lesion. ( $a$ and b) Patient with craniopharyngioma confined to the intrasellar space $\left(0^{\circ}=\right.$ no hypothalamic involvement (a)/surgical lesion (b)). BMI at diagnosis: -0.11 s.D.; BMI 36 months after complete resection: -0.41 s.D. (c and d) Patient with craniopharyngioma involving the anterior hypothalamus $\left(I^{\circ}=\right.$ hypothalamic involvement (c)/surgical lesion of the anterior hypothalamic area (d)). BMI at diagnosis: -1.75 s.D.; BMI 36 months after complete resection: -0.43 s.D. (e and f) Patient with craniopharyngioma involving the anterior and posterior hypothalamus $\left(\mathrm{II}^{\circ}=\right.$ hypothalamic involvement $(\mathrm{e}) /$ surgical lesion of the anterior and posterior hypothalamic area (f)). BMI at diagnosis: +6.08 s.D.; BMI 36 months after complete resection: +6.79 s.D. Arrows indicate mammillary bodies, defining the border between anterior and posterior involvement/lesion. 

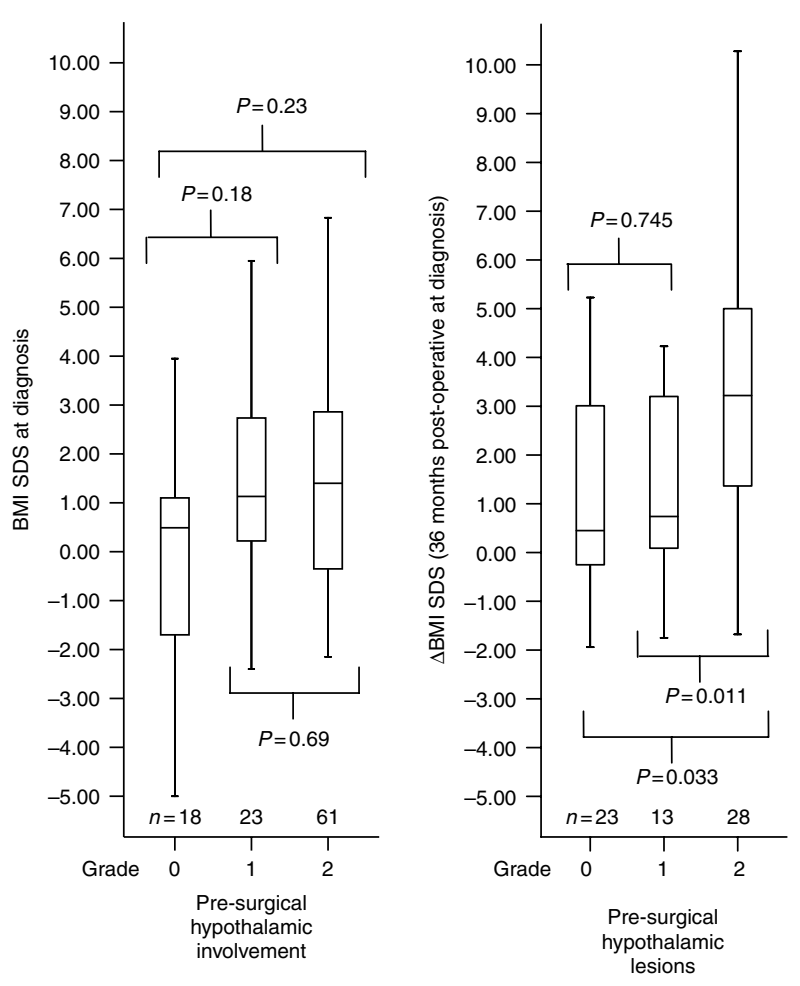

Figure 2 Body mass index (BMI SDS) at diagnosis (a) and increase in BMI ( $\triangle$ BMI SDS) during 36 months after surgery (b) in relation to presurgical hypothalamic involvement (a) and surgical hypothalamic lesions (b) of 117 childhood craniopharyngioma patients recruited in KRANIOPHARYNGEOM 2000 (missing data in 3/120 patients). The horizontal line in the middle of the box depicts the median. Edges of box mark the 25th and 75th percentile. Whiskers indicate the range of values that fall within 1.5 box-lengths.

grade $1\left(\mathrm{I}^{\circ}\right)$, hypothalamic involvement/lesion of the anterior hypothalamus not involving the mammillary bodies and the hypothalamic area beyond mammillary bodies (Fig. 1c and d); and grade $2\left(\mathrm{II}^{\circ}\right)$, hypothalamic involvement/lesion of the anterior and posterior hypothalamic area, i.e. involving the mammillary bodies and the area beyond mammillary bodies (Fig. 1e and f).

\section{Statistical analysis of results}

For comparison of normally distributed variables among groups, unpaired $t$-tests and unifactorial ANOVA were used. For comparison of not normally distributed variables among groups, Mann-Whitney $U$ tests and Kruskal-Wallis tests were used. Boxplots and $P$ values are given for illustration. For comparison of a categorical variable among groups, the generalised exact Fisher's test was used. Crosstabs and $P$ values are given for illustration.

A multivariable analysis for the increase of dependent variable in BMI within 36 months after diagnosis was done with a general linear model. The following variables were analysed: pre-surgical hypothalamic involvement $\left(0^{\circ}\right.$ versus $\mathrm{I}^{\circ}$ versus $\left.\mathrm{II}^{\circ}\right)$, hypothalamic lesion $\left(0^{\circ}\right.$ versus $\mathrm{I}^{\circ}$ versus $\left.\mathrm{II}^{\circ}\right)$, tumour volume (continuous), centre size (large-sized versus middlesized versus small-sized centres), intention to treat (radical versus incomplete intention to treat), degree of resection (complete versus incomplete surgical resection) and relapse or progression within the 36 months (yes versus no). All analyses were explorative. Statistical analyses were performed by IMBEI using SPSS 15.0 (Chicago, IL, USA).

\section{Results}

Based on the expected incidence rate (0.5-2.0 cases per million persons per year) of childhood craniopharyngioma $(1,2)$, the cohort analysed in KRANIOPHARYNGEOM 2000 indicated a high degree of completeness $(>95 \%)$ in recruitment.

The degree of obesity (BMI SDS) at diagnosis was similar in patients with different grades of hypothalamic tumour involvement $\left(0^{\circ}-\mathrm{II}^{\circ}\right)$ (Fig. 2a). Differences in terms of age at diagnosis, gender distribution and prediagnosis duration of condition were non-detectable among patients with different grades of pre-surgical hypothalamic involvement (data not shown). Univariable analysis revealed that surgical hypothalamic lesions of both anterior and posterior hypothalamic areas $\left(\mathrm{II}^{\circ}\right)$ were associated with higher increase in BMI SDS (II : $\Delta+3.22$ BMI SDS) during the first 36 months after diagnosis in comparison to patients with no or only anterior lesion $\left(0^{\circ}: \Delta+0.45\right.$ BMI SDS, $P=0.033 ; I^{\circ}: \Delta+0.74$ BMI SDS, $P=0.011$ respectively).

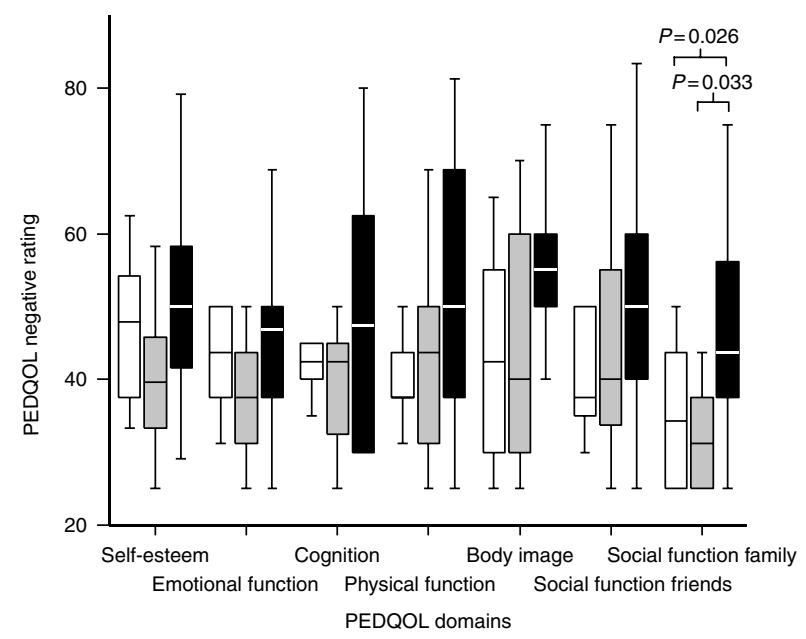

Figure 3 Quality of life (PEDQOL score for domains of the instrument) at 36 months after diagnosis of 117 childhood craniopharyngioma patients recruited in KRANIOPHARYNGEOM relative to the extent of surgical hypothalamic lesions (grade 0 depicted as open white boxes, grade 1 depicted as hatched boxes and grade 2 depicted as filled black boxes). The horizontal line in the middle of the box depicts the median. Edges of box mark the 25th and 75 th percentile. Whiskers indicate the range of values that fall within 1.5 box-lengths. 


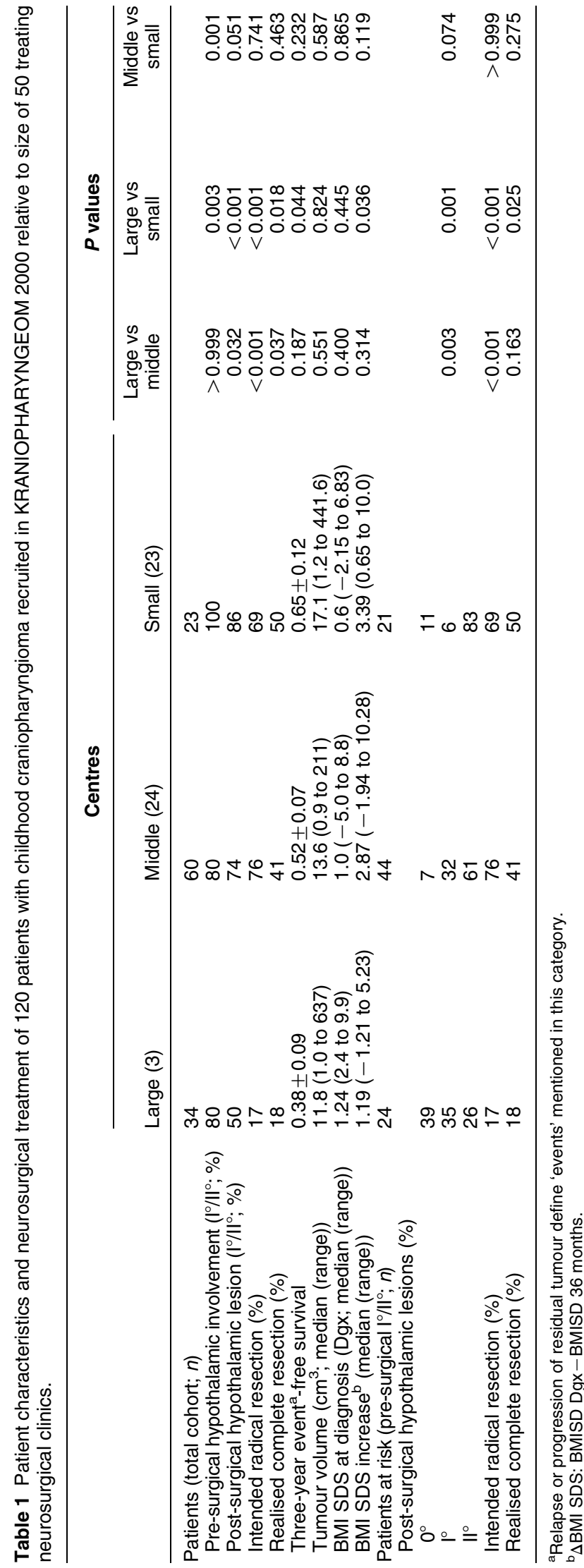

Patients without hypothalamic lesions $\left(0^{\circ}\right)$ and anterior hypothalamic lesion $\left(\mathrm{I}^{\circ}\right)$ developed only modest increase in BMI SDS during the first 36 months after diagnosis/ surgery (Fig. 2b). The degree of hypothalamic surgical lesions had negative impact on health-related QoL as measured by PEDQOL after 36 months of follow-up (overall $P=0.020$, ANOVA). Patients with $\mathrm{II}^{\circ}$ lesions had lowest self-assessed QoL for the PEDQOL domain 'social function family' $(P=0.013$; Fig. 3$)$.

Patient characteristics and neurosurgical treatment strategies varied among the 50 neurosurgical centres (three large-sized centres with 34 patients, 24 middlesized centres with 60 patients and 23 small-sized centres with 23 patients during the recruitment period; missing data in 3/120 patients). Patients treated in small-sized centres presented with a higher pre-surgical rate of hypothalamic involvement $\mathrm{II}^{\circ}$ compared with the middle-sized $(P=0.001)$ and large-sized centres $(P=0.003)$. In large centres, the intention to treat was less radical in comparison with middle-sized $(P<0.001)$ and small-sized centres $(P=0.001)$. The rates of complete resections and hypothalamic surgical lesions were lower for patients treated in large centres when compared with patients treated in middle-sized $(P=0.037 ; \quad P=0.032)$ and small-sized centres $(P=0.018 ; P<0.001)$ respectively. These findings could also be confirmed for the subgroup of patients with pre-surgical hypothalamic involvement $\left(\mathrm{I}^{\circ}\right.$ and $\left.\mathrm{II}^{\circ}\right)$ (Table 1). The 36-month, post-surgical self-assessed QoL in the domain 'social function friends' was lower in patients treated at small-sized centres compared with patients treated at middle- or large-sized centres $(P=0.018, P=0.068$, respectively, Fig. 4$)$.

A multivariable analysis of seven assessed risk factors for the development of severe obesity (hypothalamic involvement and lesion, tumour volume, centre size, intention to treat, degree of resection and relapse/ progression within 36 months after diagnosis) showed that pre-operative hypothalamic involvement $\left(\mathrm{II}^{\circ}\right)$ was the only independent risk factor for changes in BMI SDS during 36 months of follow-up $(P=0.002$; anterior and posterior: $\Delta+2.7$ BMI SDS in comparison to patients with no involvement, $\Delta+0.8$ BMI SDS for patients with anterior involvement in comparison to patients without involvement).

\section{Discussion}

We analysed KRANIOPHARYNGEOM 2000 multinational prospective 3-year follow-up data evaluating factors that potentially affect the prognosis and QoL of childhood craniopharyngioma patients: hypothalamic involvement, tumour volume, degree of resection, surgical hypothalamic lesions, relapse/progression of residual tumour and centre size of participating neurosurgical clinics. The cohort analysed reflects a high degree of completeness $(>95 \%)$ in recruitment 


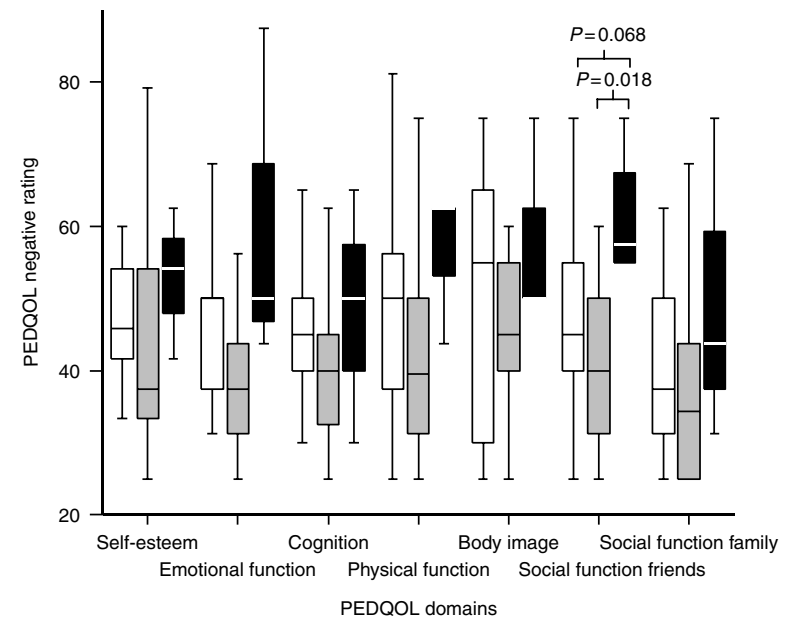

Figure 4 Quality of life (PEDQOL score for domains of the instrument) at 36 months after diagnosis of 117 childhood craniopharyngioma patients recruited in KRANIOPHARYNGEOM 2000 relative to neurosurgical centre size based on the patient load during recruitment. Large-sized centres (more than five patients/6 years) are depicted as open white boxes, middle-sized centres (two to five patients/ 6 years) are depicted as hatched boxes and smallsized centres (one patient/ 6 years) depicted as filled black boxes. The horizontal line in the middle of the box depicts the median. Edges of box mark the 25th and 75th percentile. Whiskers indicate the range of values that fall within 1.5 box-lengths.

based on the known incidence rate (0.5-2.0 cases per million persons per year) of childhood craniopharyngioma $(1,2)$.

De Vile et al. $(9,10)$ have shown that hypothalamic lesions positively correlated with weight gain during follow-up. However, the authors analysed postoperative weight development mainly in relation to postoperative hypothalamic damage. Our grading system includes preoperative assessment of hypothalamic involvement. We have chosen the mammillary bodies as a specific landmark for the differential grading of anterior or posterior involvement/lesion, because in craniopharyngioma, even for large sellar masses with hypothalamic involvement the mammillary bodies can be recognised on MRI (especially in T2 sequences) most of the time. Puget et al. (13) also demonstrate that treatment stratification based on a pre-surgical score of hypothalamic involvement to avoid hypothalamic damage improves the outcome and prevented sequelae. These studies are mostly based on the single-institute retrospective format. In addition, there are only a few studies analysing the outcome of patients with craniopharyngioma in relation to the neurosurgeons' experience. Sanford (14) and Boop (15) report a marked difference in outcome according to the neurosurgeons' experience with the condition.

The multinational, multi-clinic, 3-year prospective aspects of this study, the use of standardised imaging and grading schematics, coupled with the QoL selfassessment survey (PEDQOL), all help to overcome previous disadvantages in examining impact of neurosurgeons' experience as well as centre patient load on extent of surgical hypothalamic lesions and consequential QoL impact due to both pre- and post-surgical conditions. The hypothalamic involvement/lesion score we use provides a defined grading based on the identification of the mammillary bodies in MRI, bolstered by anatomical classification in anterior and posterior hypothalamic parts to improve our understanding of the pathogenic impact of different hypothalamic lesions.

Our results show that surgical treatment of craniopharyngioma affects rather radical increase in BMI SDS during the post-surgical 36-month period, especially anterior and posterior hypothalamic surgical lesions $\left(\mathrm{II}^{\circ}\right)$, with consequential severely lower QoL scores for social function family (Figs 3 and 4). In contrast to other reports in the literature (5), differences in terms of obesity (BMI SDS) at the time of diagnosis were not related to the grade of hypothalamic involvement in our cohort. Further analyses of larger prospectively evaluated cohorts are currently under process (KRANIOPHARYNGEOM 2007) to answer the question and clarify the discrepancy.

The second disturbing result is the disparity in the ratio between neurosurgical centre patient load/treatment intent: the smaller the centre patient load, the more radical the intent of treatment. One of the biggest challenges in treating craniopharyngioma is identifying the best candidates for the radical versus the conservative approach. Experiential expertise in large centres (defined as the number of operations per year) in western countries has increased the possibility of safe gross total resection, evidenced by two reports representing historically different attitudes: the first at Necker Hospital (13), which is more surgically oriented, and the second in North America (16), which is more oriented towards a conservative approach. The North American experience shows that most recent cases now receive moderate or aggressive surgery and only $42 \%$ have limited surgery before irradiation. The Necker study authors (13) show in a contemporary study that $96 \%$ of their recent cases achieve complete $(23 \%)$ or subtotal resection $(73 \%)$ and that radiotherapy is performed in $50 \%$ of cases after subtotal resection. It appears that there is a trend towards radiotherapy in centres with past prevalent surgical approaches and towards continuation of surgical treatment in centres historically conservative oriented. A big challenge for future studies is to try to define an 'intermediate approach' using clear objective criteria to identify the best candidates for the radical versus the conservative approach. Our grading system of hypothalamic involvement might help to achieve a more risk-adapted surgical strategy.

There are no randomised, controlled studies on the treatment of childhood craniopharyngioma. Reports in the literature mainly refer to single-centre, 
heterogeneous groups of patients that were retrospectively analysed. Because craniopharyngioma is a rare disease, children and adolescents with craniopharyngioma should be documented uniformly in prospective studies. There are current prospective studies in process on a national and multinational level to adopt strategies tailored to risk factors for morbidity and QoL $(1,2,13,16-18)$.

We conclude that radical excision surgery is not an appropriate treatment strategy in patients with childhood craniopharyngioma and hypothalamic involvement, especially in cases with involvement of posterior hypothalamic areas $\left(\mathrm{II}^{\circ}\right)$. For patients having undergone incomplete resection, innovative post-operative treatment strategies are warranted due to high progression rates of residual tumour. Accordingly, in KRANIOPHARYNGEOM 2007, QoL and survival rates in patients (age $\geq 5$ years at incomplete resection) are currently being analysed after randomisation of the time point of irradiation following incomplete resection (immediate irradiation versus irradiation at progression of residual tumour).

Based on our results and those in the literature, it is advisable to have a multidisciplinary team able to discuss treatment strategies, adopting sophisticated approaches based on sufficient in-house surgical and radiotherapy experience in the treatment of childhood craniopharyngioma. Furthermore, we conclude that initial hypothalamic tumour involvement, especially when both anterior and posterior areas are involved, has an apriori effect on the clinical course. Therefore, our recommendations are based on recognising childhood craniopharyngioma as a chronic disease requiring commensurate monitoring and medical resources for treatment and follow-up in order to provide the best lifetime QoL for the patient.

\section{Declaration of interest}

The authors declare that there is no conflict of interest that could be perceived as prejudicing the impartiality of the research reported.

\section{Funding}

H L Müller is supported by a grant from the Deutsche Kinderkrebsstiftung (German Children's Cancer Foundation), Bonn, Germany (grant number: DKS 2001.4).

\section{Acknowledgements}

The authors are grateful for the help of Mrs Neff-Heinrich, Göttingen, Germany, in proofreading and editing the manuscript.

This paper was presented in part at the 92nd Annual Meeting of the Endocrine Society, San Diego CA, USA 2010.

\section{References}

1 Garré ML \& Cama A. Craniopharyngioma: modern concepts in pathogenesis and treatment. Current Opinion in Pediatrics 200719 471-479. (doi:10.1097/MOP.0b013e3282495a22)
2 Müller HL. Childhood craniopharyngioma - current concepts in diagnosis, therapy and follow-up. Nature Reviews. Endocrinology 20106 609-618. (doi:10.1038/nrendo.2010.168)

3 Bunin GR, Surawicz TS, Witman PA, Preston-Martin S, Davis F \& Bruner JM. The descriptive epidemiology of craniopharyngioma. Neurosurgical Focus 199790 984-985. (doi:10.3171/ foc.1997.3.6.4)

4 Roth C, Wilken B, Hanefeld F, Schröter W \& Leonhardt U. Hyperphagia in children with craniopharyngioma is associated with hyperleptinemia and a failure in the down regulation of appetite. European Journal of Endocrinology 1998138 89-91. (doi:10.1530/eje.0.1380089)

5 Harz KJ, Müller HL, Waldeck E, Pudel V \& Roth C. Obesity in patients with craniopharyngioma: assessment of physical activity and food intake. Journal of Clinical Endocrinology and Metabolism 200388 5227-5231. (doi:10.1210/jc.2002-021797)

6 Lustig RH, Hinds PS, Ringwald-Smith K, Christensen RK, Kaste SC, Schreiber RE, Rai SN, Lensing SY, Wu S \& Xiong X. Octreotide therapy of pediatric hypothalamic obesity: a doubleblind, placebocontrolled trial. Journal of Clinical Endocrinology and Metabolism 200388 2586-2592. (doi:10.1210/jc.2002-030003)

7 Roth C, Hunneman DH, Gebhardt U, Stoffel-Wagner B, Reinehr T \& Müller HL. Reduced sympathetic metabolites in urine of obese patients with craniopharyngioma. Pediatric Research $2006 \mathbf{6 1}$ 496-501. (doi:10.1203/pdr.0b013e3180332cd6)

8 Müller HL, Faldum A, Etavard-Gorris N, Gebhardt U, Oeverink R, Kolb R \& Sörensen N. Functional capacity, obesity and hypothalamic involvement - cross-sectional study on 212 patients with childhood craniopharyngioma. Klinische Padiatrie 2003215 310-314. (doi:10.1055/s-2003-45499)

9 De Vile CJ, Grant DB, Kendall BE, Neville BG, Stanhope R, Watkins KE \& Hayward RD. Management of childhood craniopharyngioma: can the morbidity of radical surgery be predicted? Journal of Neurosurgery 199685 73-81. (doi:10.3171/jns.1996. 85.1.0073)

10 De Vile CJ, Grant DB, Hayward RD, Kendall BE, Neville BGR \& Stanhope R. Obesity in childhood craniopharyngioma: relation to post-operative hypothalamic damage shown by magnetic resonance imaging. Journal of Clinical Endocrinology and Metabolism 199681 2734-2737. (doi:10.1210/jc.81.7.2734)

11 Müller HL, Emser A, Faldum A, Bruhnken G, Etavard-Gorris N, Gebhardt U, Oeverink R, Kolb R \& Sörensen N. Longitudinal study on growth and body mass index before and after diagnosis of childhood craniopharyngioma. Journal of Clinical Endocrinology and Metabolism 200489 3298-3305. (doi:10.1210/jc.2003-031751)

12 Van Gompel JJ, Nippoldt TB, Higgins DM \& Meyer FB. Magnetic resonance imaging-graded hypothalamic compression in surgically treated adult craniopharyngiomas determining postoperative obesity. Neurosurgical Focus 201028 E3. (doi:10.3171/2010.1. FOCUS09303)

13 Puget S, Granett M, Wray A, Grill J, Habrand JL, Bodaert N, Zerah M, Bezerra M, Renier D, Pierre-Kahn A \& Sainte-Rose C. Pediatric craniopharyngiomas: classification and treatment according to the degree of hypothalamic involvement. Journal of Neurosurgery 2007106 3-12. (doi:10.3171/ped.2007.106.1.3)

14 Sanford RA. Craniopharyngioma: results of survey of the American Society of Pediatric Neurosurgery. Pediatric Neurosurgery 199421 39-43. (doi:10.1159/000120860)

15 Boop FA. Craniopharyngioma. Journal of Neurosurgery 2007106 1-2. (doi:10.3171/jns.2007.106.1.1)

16 Merchant TE, Kiehna EN, Kun LE, Mulhern RK, Li C, Xiong X, Boop FA \& Sanford RA. Phase II trial of conformal radiation therapy for pediatric patients with craniopharyngioma and correlation of surgical factors and radiation dosimetry with change in cognitive function. Journal of Neurosurgery $2006 \mathbf{1 0 4}$ 94-102. (doi:10. 3171/ped.2006.104.2.5)

17 Müller HL, Albanese A, Calaminus G, Hargrave D, Garré ML, Gebhardt U, Saran F, Sörensen N \& Spoudeas HA. Consensus and perspectives on treatment strategies in childhood 
craniopharyngioma - results of a meeting of the craniopharyngioma study group (SIOP), Genova 2004. Journal of Pediatric Endocrinology $\mathcal{E}$ Metabolism 200619 453-454.

18 Trivin C, Busiah K, Mahlaoui N, Recasens C, Souberbielle JC, Zerah M, Sainte-Rose C \& Brauner R. Childhood craniopharyngioma: greater hypothalamic involvement before surgery is associated with higher homeostasis model insulin resistance index. BMC Pediatrics 20099 24. (doi:10.1186/14712431-9-24)

19 Müller HL, Gebhardt U, Schröder S, Pohl F, Kortman RD, Faldum A, Zwiener I, Warmuth-Metz M, Pietsch T, Kolb R, Wiegand C \& Sörensen N. Analyses of treatment variables for patients with childhood craniopharyngioma - results of the multicenter prospective study KRANIOPHARYNGEOM 2000. Hormone Research Paediatrics 200973 175-181. (doi:10.1159/ 000284358)
20 Rolland-Cachera MF, Cole TJ, Sempé M, Tichet J, Rossignol C \& Charraud A. Body mass index variations: centiles from birth to 87 years. European Journal of Clinical Nutrition 1991 45 13-21.

21 Müller HL, Bueb K, Bartels U, Roth C, Harz K, Graf N, Korinthenberg R, Bettendorf M, Kühl J, Gutjahr P, Sörensen N \& Calaminus G. Obesity after childhood craniopharyngioma - German multicenter study on pre-operative risk factors and quality of life. Klinische Padiatrie 2001 213 244-249. (doi:10.1055/s-2001-16855)

22 Warmuth-Metz M, Gnekow A, Müller HL \& Sörensen N. Differential diagnosis of suprasellar tumors in children. Klinische Padiatrie 2004216 323-330. (doi:10.1055/s-2004-832358)

Received 8 April 2011

Accepted 12 April 2011 